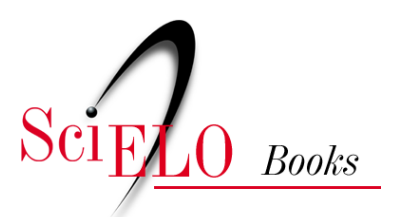

\title{
33. La Coca-Cola mata el alcohol
}

\author{
César Augusto Tapias Hernández
}

\section{SciELO Books / SciELO Livros / SciELO Libros}

TAPIAS HERNÁNDEZ, C.A. La Coca-Cola mata el alcohol. In: Historias de familia: Etnografía delirante sobre el amor, la violencia y las drogas [online]. Bogotá: Editorial Universidad del Rosario, 2014, pp. 143-146. Textos de ciencias humanas collection. ISBN: 978-958-738-543-4.

https://doi.org/10.7476/9789587385434.0034.

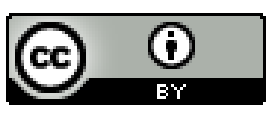

All the contents of this work, except where otherwise noted, is licensed under a Creative Commons Attribution 4.0 International license.

Todo o conteúdo deste trabalho, exceto quando houver ressalva, é publicado sob a licença Creative Commons Atribição $\underline{4.0}$.

Todo el contenido de esta obra, excepto donde se indique lo contrario, está bajo licencia de la licencia $\underline{\text { Creative }}$ Commons Reconocimento 4.0. 


\section{La Coca-Cola mata el alcohol}

¡Sí! El tiempo reina, restaurando su brutal dictadura, y con su doble aguijón me empuja, como si yo fuese un buey: “camina, asno!, jsuda, esclavo! Vive pues, ;maldito!” Charles Baudelaire, Spleen de París

El papito Fonso manda por un litro de "guaro". Yo me sorprendo: hace un buen tiempo que él no toma licor. En tanto llega el trago, lo pone en el mostrador de su tienda acompanándolo de Coca-Cola, según él, el mejor pasante. Y, así, sin más, arranca la historia tras mi pregunta:

—Fonso, ¿cómo así que vos antes tuviste una salsamentaria?

— ¡No! Yo tenía era un granero ahí en el Pedrero, un toldo que llamábamos. Lo tenía con un amigo y vendíamos de todo.

- ¿Cómo se llamaba el negocio, papito?

- ¡Con tanto granero que había por ahí! Noo, eso no tenía nombre. Era bobada ponerle nombre.

- Papito, cuénteme una historia suya de esos tiempos...

-Mmmm, a ver, hermano... Ah, sí, un día cualquiera el socio y yo entramos a un café y nos cogen los de ahí, hermano. A cascarnos, hermano, que no sé qué hijueputas y en fin... Era la época de la violencia política. Yo siempre he sido conservador. Toda la vida y nos rodearon todos los de ahí, hermano. Yo saqué la peinilla mía que era de 18 pulgadas y el amigo mío a volear taburetes, y como el cantinero era amigo de ellos, nos arrinconaron... Llegó la policía y yo tiré lo mío por allá detrás de unos bultos: ahí la perdí. Los policías eran dizque a ver que yo qué tenía. "Nada, señor agente", decía yo.

Me parecía estar viendo al tío Ed contándole a uno sus vueltas, así como hacía con el tío Hétor Mario un domingo después de sendas farras sabatinas; mientras, 
frente a la tele, iban desayunando. Y lo digo, sobre todo, por las posturas del papito cuando cuenta cómo se le arrimaron los tombos y la raqueta, y cómo pierde lo suyo, y tal y pascual...

-Yo expliqué que ellos nos habían buscado problema; pero, hablando, el amigo mío sí se rebotó, tanto así que... Fíjese el café ese donde estábamos: quedaba por allá llegando a San Juan. La estación de Policía quedaba sobre Cúcuta, como pa' los lados de las Empresa Públicas, y en ese trayecto lo iban a bajar por los lados del río (por donde hoy quedan los bomberos). Le iban era a dar la pela... A mí sí me devolvieron a la misma esquina. “Tranquilo, ombe, señor. Todo está bien”, dijeron.

Al otro día, el abuelo dizque fue a abrir el negocio y el socio no apareció. Muy al rato una llamada: que le mandara plata para poder salir. Había amanecido encanado.

- ¿Y usted entonces no volvió por allá, o qué?

—Eso se puso malo, hermano... Partimos, y a través de un paisano me coloqué en el Ferrocarril.

- ¿En el Ferrocarril de Antioquia?

- Sí. Me mandaron a trabajar a la estación del Purgatorio, por los lados de Bolombolo, en medio de un cañón GRANDE; pero esa época fue demasiado dura. Se me murieron cuatro muchachos. Yo estaba muy mal... El paisano me llevó adonde el ingeniero de allá y adonde un doctor ahí medio marica él, y me colocaron en las Empresas. Eso fue un lunes, me acuerdo. Me avisaron al otro día que me presentara a las Empresas al miércoles. Entonces yo no fui a trabajar a la Estación, y el doctor me dijo que si podía empezar ahí mismo. Yo le dije que no, porque tenía que ir a devolver las herramientas. Entonces que me presentara el sábado, fue lo que me dijo. Fui a devolver las herramientas y esa gente ya pensaba que yo no iba a volver. $\mathrm{Mi}$ paisano y el ingeniero creyeron que ni a devolver las herramientas volvería, pero no, yo fui. Que no me fuera, que quédese, que le subimos el sueldo, que lo mandamos para donde quiera, me decían ellos. Y yo que no... Yo que no. Y eso que tenía de todo allá: prima, cesantías, vacaciones, todo; pero no, yo me fui pa' las Empresas.

- ¿Por qué te rogaron tanto? ¿Eras buen camellador?

— ¿Yo? Hooombe, yo siempre he sido un verraco pa' trabajar. Desde los once años. Pa' volear pico, pala, lo que fuera, hermano. Yo me subía unos bultos que, mejor dicho. Humm... quedaba mirando no más las piedras del camino y yo párriba... Imagínese que trabajando con el hermano mayor mío, yo me ganaba el jornal de hombre: unos treinta pesos y a él le daban el de menor de edad: doce o quince. Solo porque yo trabajaba duro...

—_Por qué tan camellador, pito? 
-Tuve un tío que me enseñó a trabajar: Benigno Valencia, se llamaba ese hijueputa, porque era un hijueputa, oís. No me podía ver para’o, hermano, ni dormido, porque me tiraba o me mandaba a tirar. ¡Ah! Pero al que más le aprendí fue al negro Palacio, un tipo GRande de Yolombó... GRANDE de unos brazos y unas muñecas gruesas. GRANDE el tipo, así como como el papá de este pelao Daniel, el que levantaron Hael y Fernando, de unos músculos también GRANDES, hermano. Estábamos por allá en El Retiro y un día llegaron unos estacones de 1,80 metros para alambrados, o sea, para separar los pastos del ganado en esas fincas inmensas. Le ofrecieron el trabajo a él y le dijeron que escogiera un ayudante, y Palacio me mira y dice: "Me llevo a Fonso". Él me explicaba mientras trabajaba y me ayudaba mucho a sopesar las cargas. PERO ÉL NO PONÍA LOS ESTACONES ESOS COMO TODos, nada. Y yo después de hacer los huecos dizque a sacar la tierra con las manos y él que no, pa’ eso está la barra y con la barra aprendí a sacar la tierra esa...

- ¿Cómo se ponían los estacones esos, pues?

-No... Era normal ponerlos con piamigos por un lado y por el otro; pero con Palacio nada eso, era sin nada: cuarenta centímetros del estacón metido en tierra y eso quedaba fino y derecho... Usted miraba así (y el papito coloca su mano al frente, como entre sus dos ojos y mira a lo lejos siguiendo el movimiento de la misma mano: al frente): y no era una fila de estacones por ahí puestos lo que usted veía... nada hermano, usted veía nada más que un estacón de lo derecho que quedaba eso, hermano... El primer estacón nada más.

- ¿Cómo fue la cosa en las Empresas?

- Bueno, el primer día en las Empresas me mandaron para acá, a los filtros de El Pedregal-Santander. Caminaba desde Bello para poder llegar, como vivíamos por allá. Después pagué alquiler en Santander hasta que conseguí este lote: \$7200 fue el préstamo para empezar a construir.

- ¿Y cómo era eso, el terreno y ya, ni una pieza?

— ¡Nada! Eso era una entrada a la cuadra y a los lados unos plancitos hechos por la misma máquina que hacía la entrada a la cuadra, de inmediato uno a abrir huecos pa' las cepas. La construcción era por cuenta de uno, con un préstamo del Instituto de Crédito Territorial. Todo eso se pagó en quince años, por cuotas...

La mamita Gélica se ha unido a la improvisada bebeta sobre el mostrador de la tienda.

—QQué 24 de diciembre más apagado! 
Y donde "Los Monos" extrañados que porque este año no había rumba donde los Tales... Ni donde los Tales, ni tampoco en más de una casa de por aquí, como donde los Madrid...

-Es que a doña Filomena apenas la operaron en estos días y le pusieron unas platinas... Y no ha estado como muy bien. Cuenta la abuela.

Un trago. Uno para cada uno.

A la mamita no le gusta pasar los guaros con nada, mucho menos con CocaCola, como lo hace el papito, dice que la Coca-Cola Mata el alcohol y entonces... ¡Qué gracia! 